\title{
O PROFESSOR E OS NOVOS CONTEXTOS DE ENSINO: UMAABORDAGEM TEÓRICO-METODOLÓGICA EM TEMPOS DE PANDEMIA ${ }^{1}$
}

\author{
THE TEACHER AND THE NEW TEACHING CONTEXTS: A THEORETICAL \\ METHODOLOGICAL APPROACH IN TIMES OF PANDEMIC
}

\author{
Rafaela Luana Zurawski ${ }^{2}$, Noemi Boer ${ }^{3}$ e Neusa Maria John Scheid ${ }^{4}$
}

\section{RESUMO}

Objetiva-se, neste estudo, caracterizar os novos contextos de ensino para compreender o papel do professor em tempos de mudança, impostos pela crise sanitária e humanitária, em virtude da pandemia Covid-19. O estudo, de cunho bibliográfico e de natureza descritiva, defende a ideia de que o ensino escolar e o trabalho do professor estão em constante diálogo com o meio social, haja vista que os fenômenos socioambientais afetam diretamente a vida na escola. No isolamento social, durante a suspensão das aulas presenciais e nas ações necessárias para evitar o contágio pelo novo Coronavírus, as mídias sociais se tornaram a única forma de comunicação entre estudantes e professores. Essa situação apresenta-se como um desafio a muitos docentes que não estavam acostumados aos meios eletrônicos para uma função educativa, exigindo-lhes adaptação, assim como, igualmente, de alunos e de seus familiares. Nesse contexto, constata-se o incremento da busca por formação continuada pelos professores, por meio de cursos de curta duração, nomeadamente para a capacitação no uso de tecnologias digitais. A busca em sites informativos, com a finalidade de atualização relativa à pandemia, cresceu significativamente. Consoante a isso, os professores investigam alternativas motivadoras à sequência de seu trabalho laboral, na tarefa educativa em curso. Aprender a cuidar de si, para poder ensinar os outros, é a competência mais necessária nesse crucial momento. Dessa forma, reafirma-se o compromisso profissional, a dedicação e a constante formação dos docentes diante das incertezas que afetam a educação no momento.

Palavras-chave. Formação de professores, Desafios docentes, Aprendizagem.

\section{ABSTRACT}

The objective of this study is to characterize the new teaching contexts to understand the role of the teacher in times of change, imposed by the health and humanitarian crisis, due to the Covid-19 pandemic. The study, of bibliographic and descriptive natures, defends the idea that school teaching and the teacher's work are in constant dialogue with the social environment, given that socio-environmental phenomena directly affect life at school. In social isolation, during the suspension of face-to-face classes and in the actions necessary to avoid contamination of the new Coronavirus, social media has become the only form of communication between students and teachers. This situation presents itself as a challenge to many teachers who were not used to electronic means for an educational function, requiring adaptation, as well as, equally, students and their families. In this context, there is an increase in the search for continuing education by teachers, through short courses, namely for training in the use of digital technologies. The search on informational sites for the purpose

\footnotetext{
${ }^{1}$ Artigo resultante de um trabalho científico no grupo de pesquisa em Ensino de Ciências, Tecnologia e Saúde (GPECTS)

${ }^{2}$ Mestranda. Programa de Pós-graduação em Ensino Científico e Tecnológico - PPGEnCT. Universidade Regional Integrada do Alto Uruguai e das Missões- URI - Campus de Santo Ângelo. E-mail: rafaelalzurawski@aluno.santoangelo.uri.br ${ }^{3}$ Professora da Universidade Regional Integrada do Alto Uruguai e das Missões- URI - Campus de Santo Ângelo e Universidade Franciscana - UFN. E-mail: noemiboer@gmail.com

${ }^{4}$ Professora da Universidade Regional Integrada do Alto Uruguai e das Missões- URI - Campus de Santo Ângelo. E-mail: scheid.neusa@gmail.com
} 
of updating on Pandemic has grown significantly. Accordingly, teachers investigate motivating alternatives to the sequence of their work, in the ongoing educational task. Learning to take care of themselves, in order to be able to teach others, is the most necessary competence in this crucial moment. Thus, the professional commitment, dedication and constant training of teachers is reaffirmed in the face of the uncertainties that affect education at the moment.

Keywords: Teacher training, Teaching challenges, Learning.

\section{INTRODUÇÃO}

Vive-se em uma sociedade marcada por muitas diferenças e desigualdades sociais e, agora, agravada por uma pandemia que fez milhares de vítimas em todo os continentes. Esses problemas sociais afetam diretamente as instituições de ensino, os professores e a vida dos estudantes, que se viram obrigados a migrar para uma nova modalidade de ensino, até então, pouco difundida nos cursos presenciais. Isso exigiu do professor a busca de novas formas e estratégias de ensino e colocou a escola em um novo patamar de relação entre professor-aluno-conteúdo.

Em virtude da pandemia, gerada pela doença Covid-19, tudo mudou. No isolamento social, durante a suspensão das aulas presenciais e nas ações necessárias para evitar o contágio pelo novo Coronavírus, as mídias sociais se tornaram a única forma de comunicação entre estudantes e professores. Com isso, as desigualdades sociais ficaram ainda mais evidentes, tendo em vista que uma parcela significativa de estudantes não tem acesso à internet de qualidade e a outras mídias. Para o atendimento remoto, os professores precisaram buscar novas formas de ensinar, mediadas pela tecnologia. Essa situação apresenta-se como um desafio para muitos professores que não estão acostumados a utilizar meios eletrônicos para uma função educativa, exigindo adequação à nova realidade social e ambiental.

Diante desse cenário, “o mais importante é a necessidade de o país ter uma ciência forte e instituições científicas e universitárias onde se possa gerar conhecimento para compreender a dinâmica da doença na relação com a sociedade e o ambiente, e também apoiar o desenvolvimento de políticas públicas", defende a presidente da Fiocruz ${ }^{5}$, Nísia Trindade Lima (DAHER, 2020, p. 7). Paralelo às preocupações com a ciência, que precisa dar uma resposta urgente à humanidade, o ensino escolar e a educação são questões centrais neste momento de pandemia, porque envolvem milhões de estudantes, professores e famílias brasileiras.

A garantia de uma educação voltada aos processos formativos e de desenvolvimento do ser humano, inspirada nos princípios de liberdade e nos ideais de solidariedade, como dever da família e do Estado, está prevista na Lei de Diretrizes e Bases da Educação Nacional (BRASIL, 1996). Assim, a educação escolar tem como objetivo trabalhar o desenvolvimento cognitivo dos estudantes, mas também a formação integral, no intuito de conduzi-los à preparação da vida e às situações que irão

\footnotetext{
${ }^{5}$ Fiocruz, instituição brasileira, criada há 120 anos, é referência no combate às epidemias e modelo no enfrentamento da Covid-19 nas Américas.
} 
ocorrer ao longo do caminho. No Brasil, garantir o acesso à educação básica é um dever do Estado e um direito de todo cidadão. A educação é indispensável para uma sociedade democrática, pois, com ela, o ser humano adquire conhecimentos necessários para pensar realmente nas coisas que acontecem no meio em que vive e mudá-las, se for preciso.

A Base Nacional Comum Curricular (BNCC) busca garantir o direito à aprendizagem e ao desenvolvimento pleno do aluno, procura nortear também a igualdade de todo sistema educacional para uma formação integral, construindo, assim, uma sociedade democrática, justa e inclusiva (BRASIL, 2018).

O processo educacional passa por constantes modificações ao longo do tempo, alterando, assim, os contextos de ensino e, consequentemente, as práticas dos professores. Em vista disso, neste estudo, tem-se por objetivo caracterizar os novos contextos de ensino para compreender o papel do professor em tempos de mudança, impostos pela crise sanitária e humanitária, em virtude da pandemia gerada pela Covid-19. Elencam-se, também, algumas lições aprendidas com a crise instalada.

Para isso, organizou-se o artigo em quatro seções, além da introdução e das considerações finais. Inicialmente, descreve-se o delineamento metodológico do estudo; na sequência, apresentam-se os antigos e novos contextos de ensino e, na terceira seção, discorre-se a respeito do professor e de sua necessidade de se reinventar. Com tom reflexivo, na quarta seção, identificam-se alguns aspectos denominados de lições diante do atual cenário.

\section{METODOLOGIA}

No delineamento metodológico deste estudo, apresenta-se uma abordagem qualitativa, caracterizada como estudo de revisão, seguida das etapas da pesquisa bibliográfica, que inicia com a escolha do tema, a identificação de uma problemática a ser descrita, a definição dos objetivos do estudo, o levantamento preliminar de fontes, leitura e fichamento do material, necessários à redação do texto (GIL, 2017).

A técnica da pesquisa bibliográfica está embasada em materiais elaborados por outros autores, por meio de fontes secundárias, decorrentes de pesquisas anteriores, disponíveis em documentos escritos, livros, artigos científicos, dissertações e teses. Em vista disso, o pesquisador utiliza dados ou categorias teóricas já trabalhadas por outros autores, cujos textos tornam-se fonte de pesquisa (SEVERINO, 2007).

Desse modo, os documentos de análise, utilizados neste estudo, são a lei de Diretrizes e Bases da Educação Nacional (LDB), (BRSIL, 1996); a Base Nacional Comum Curricular (BNCC) (BRASIL, 2018); Programa Todos pela Educação (2020); Diretrizes Curriculares Nacionais para a Formação Inicial e Continuada de Professores da Educação Básica: BNC-Formação (BRASIL, 2019). Além desses documentos, foram utilizados textos de autores como Nóvoa (2009); Blanchard y Muzás (2016); Fazenda (2002); Behrens (2008); Morin (2000) e Santos (2020). 
Nessa direção, a pesquisa refere-se ao atual momento da Covid-19 cujos desafios educacionais se intensificaram enormemente, mas é necessário compreender também a atuação do professor, em tempo de mudança extraordinária como a que vivemos no momento.

\section{O ENSINO ESCOLAR EM ANTIGOS E NOVOS CONTEXTOS}

O ensino escolar, por diversos motivos, sempre é pauta de discussão, seja pela qualidade do ensino da educação básica seja pelas constantes transformações sociais. A verdade é que as famílias também se organizam em função da educação escolar de seus filhos. Em vista disso, e diante das transformações sociais, decorrentes da crise sanitária, geradas pela doença Covid-19, o ensino escolar precisou ser reestruturado.

A escola não é a mesma de alguns meses atrás: mudou a funcionalidade e a modalidade escolar. Observa-se que algumas ferramentas e metodologias se tornaram insuficientes para suprir o atual cenário educacional, em que muitas redes de ensino suspenderam as aulas presenciais e passaram ao uso de meios digitais de aprendizagem.

De acordo com uma nota técnica do Programa Todos pela Educação, "é preciso ter expectativas realistas quanto às diversas soluções existentes, sabendo que elas são importantes alternativas no atual momento, mas não suprirão todas as necessidades acadêmicas esperadas e previstas nos currículos" (2020, p. 7). Cabe ressaltar o alerta desse Programa para a possibilidade de, apesar dos esforços dos professores, as escolas não conseguirem atender a todas as necessidades esperadas e previstas nos currículos. Com isso, podem comprometer a aquisição de conhecimentos e a aprendizagem dos estudantes.

Na sequência, esse documento enfatiza: “Ainda que existam tecnologias educacionais promissoras, seus resultados positivos vêm quando são utilizadas em conjunto com atividades escolares presenciais, que envolvem interação dos alunos com professores, tutores e entre si, ou seja, não totalmente virtual (TODOS PELA EDUCAÇÃO, 2020, p. 7). Como consta nessa citação, o documento acena para um ensino híbrido, pois poderia atender a uma parcela maior de demandas e de interesses. No entanto, ainda não há consenso a respeito da eficácia dessa modalidade de ensino na educação básica.

Acreditava-se que alunos e professores estavam cada vez mais autônomos por conta das tecnologias e pelas informações mais acessíveis. No entanto, o que se observa são professores cansados, virando praticamente YouTubers ${ }^{6}$, para tentarem dar conta dos conteúdos e atividades escolares. No contraponto, alunos perdidos em meio a tudo isso. O que aconteceu foi uma mudança brusca, quase inesperada, que tornou o trabalho docente mais desafiador e complexo, pois, em algumas realidades, a presença das tecnologias vinha acontecendo de forma tímida nas salas de aula.

\footnotetext{
6 "Segundo verbete do dicionário Oxford, YouTubers é um usuário frequente do site de compartilhamento de vídeos YouTube, especialmente alguém que produz e aparece em vídeos no site” (KURTZ, 2016).
} 
Não se pode negar que as tecnologias e mídias sociais revolucionam os modos de ensinar e aprender, mas o que fazer quando os professores não estão preparados para ensinar de forma virtual? E o que fazer quando os alunos também não estão preparados para receber esses conteúdos em forma de ensino remoto, que exige deles uma maior autonomia para estudar?

Para isso, sem dúvida, são necessárias inovadoras estratégias de ensino para auxiliar no desenvolvimento dos alunos, procurando mostrar a contextualização dos conteúdos escolares. Para isso, é importante relacioná-las a elementos que fazem parte da realidade atual, para que os conteúdos façam sentido à vida dos estudantes.

Se antes da pandemia, desencadeada pela Covid-19, as tecnologias já eram um desafio para a escola e professores, agora que o ensino está completamente remoto, o desafio é muito maior, transformando a tecnologia na maior aliada da educação e dos professores.

Nesse sentido, diante do atual cenário, os professores precisam aperfeiçoar as formas de ensinar. Demo (2008, p. 134) ressalta um aspecto importante na aprendizagem: “Temos que cuidar do professor, pois todas as mudanças só entram bem na escola se entrarem pelo professor, ele é a figura fundamental". Não há como substituir o professor. Com isso, defende-se, aqui, que não há tecnologia que substitua a função do professor, como mediador dos processos de ensino e aprendizagem. A tecnologia é apenas uma ferramenta que, quando usada adequadamente, facilita a compreensão do conhecimento.

No atual cenário de ensino remoto, os professores, com vários estudantes conectados em uma aula virtual, explicam conceitos, pedem paciência e repetem pontos teóricos tantas quantas vezes for preciso. Isso tudo acaba se tornando desgastante para os professores, alunos e para os próprios pais que precisam, querendo ou não, auxiliar seus filhos nas atividades. Essa constatação é reforçada pelo seguinte argumento: "Como apontam as evidências das Ciências da Aprendizagem, a tecnologia educacional não deve se resumir a plataformas de aulas online, com slides disponíveis, professores sendo filmados e exercícios a serem feitos" (TODOS PELA EDUCAÇÃO, 2020, p. 11). Em vista disso, é preciso diversificar as experiências de aprendizagem, fazendo uso de diferentes jogos, visitas a museus virtuais, simulações, uso de laboratórios remotos e uma série de outros recursos, disponíveis em diferentes plataformas.

O ensino remoto não pode ser como aula presencial, isto é, os professores não devem dar aulas expositivas por muito tempo, é necessário procurar motivar o aluno com desafios, questionamentos, trabalhos em grupo, atividades de pesquisa, entre tantas possibilidades metodológicas. De acordo com Lopes (2011, p. 43), aula expositiva acaba "por provocar comodismo ou passividade dos alunos que se limitam a absorver tudo o que o professor fala". Uma crítica nesse sentido é feita por Lima (2008, p. 99) que considera a aula expositiva uma herança do final da Idade Média, “quando o modelo educativo idealizado pelos jesuítas se tornou referência pedagógica". Uma das consequências desse modelo é a relação verticalizada entre professor e aluno. O professor coloca-se como detentor do saber e responsável pela transmissão do conhecimento ao aluno, que está numa posição de subordinação em relação ao saber e ao professor. 
Acredita-se que a melhor forma, para que o aluno construa seu conhecimento, seja trabalhar com projetos, nos quais os próprios estudantes pesquisam a respeito das questões postas nas aulas. Nesse caso, o professor desempenha a função de mediador e não de transmissor de conteúdo. Os projetos são propostos para os estudantes aprenderem a “[...] estudar, a pesquisar, a procurar informações, a exercer a crítica, a duvidar, a argumentar, a opinar, a pensar, a gerir as aprendizagens, a refletir coletivamente e, o mais importante, são elaborados e executados com as crianças e não para as crianças" (BARBOSA; HORN 2008, p. 34). Com isso, as sugestões do professor devem se transformar num plano ou projeto que passa a ser assumido pelo grupo de alunos. Isso minimiza a ideia de imposição, e o trabalho pedagógico torna-se dialogado.

Cabe, ainda, destacar que os projetos de ensino têm sentido de proposição de uma prática pedagógica crítica, reflexiva e problematizadora, atingindo uma visão transdisciplinar. A denominação de projeto também tem sentido de provocar possibilidades ou escolhas de uma situação-problema (BEHRENS, 2008). Essa autora explica que "a metodologia de projetos que atenda a uma visão de educação complexa, global, holística e emergente, exige processos democráticos de escolha e de desenvolvimento" (2008, p. 37). Assim, a opção por metodologia de projetos requer uma visão de totalidade, possibilitando conexão entre as diversas áreas do conhecimento.

Blanchard y Muzás (2016) defendem uma educação centrada no aluno em que, na metodologia de projetos de aprendizagem, o professor, como mediador, dá a "chave" para que o aluno descubra o sentido da aprendizagem. Segundo essas autoras, o que mais importa é o que acontece no interior do aluno e não tanto o conhecimento em si. Nessa abordagem de ensino, o aluno é o protagonista do processo de sua aprendizagem. Isso requer um currículo escolar aberto, contextualizado e uma prática educativa centrada no espírito crítico-reflexivo, com avaliação formativa ao longo do processo.

Nessa linha de raciocínio, a interdisciplinaridade é um complemento ao conhecimento escolar, mostrando que os conteúdos podem ser abordados, em conjunto, por meio da integração de diferentes componentes curriculares. Segundo Fazenda (2002, p. 40), “a interdisciplinaridade pressupõe basicamente uma intersubjetividade, não pretende a construção de uma superciência, mas uma mudança frente ao problema do conhecimento, uma substituição da concepção fragmentada para a unitária do ser humano". Portanto, o processo de ensino escolar demanda atualização constante e os desafios impostos ao professor exigem aperfeiçoamento da docência, para que suas práticas demonstrem solidez e eficácia em todos os momentos.

\section{A FORMAÇÃO DO PROFESSOR E A CORAGEM DE SE REINVENTAR}

Conforme mencionado anteriormente, a situação da pandemia, gerada pela Covid-19, fez com que os professores se reinventassem e adequassem seu planejamento e suas aulas para o ensino remoto. Ser professor, neste momento de crise sanitária e humanitária, não é fácil. Por isso, reafirma-se o 
compromisso profissional, a dedicação e a constante formação diante de uma demanda desafiadora, até então, desconhecida.

Cabe, portanto, o destaque à importância da pessoa do professor para a sociedade. O professor é um profissional "do humano que ajuda o desenvolvimento pessoal e intersubjetivo do aluno, sendo um facilitador de seu acesso ao conhecimento; é um ser de cultura que domina sua área de especialidade científica e pedagógico-educacional e seus aportes para compreender o mundo" (PIMENTA; LIMA, 2012, p. 88). Essas autoras também apontam o professor como "um analista crítico da sociedade, que nela intervém com sua atividade profissional; um membro de uma comunidade científica, que produz conhecimento sobre sua área e sobre a sociedade" (2012, p. 88).

Nesses termos, o professor precisa reunir uma variedade de habilidades, conhecimentos de diferentes áreas, pois a complexidade do fazer docente e da própria educação é desafiadora, principalmente, em tempos de mudança. Professores acomodados que não buscam a inovação não cabem mais nesse novo perfil de escola e de ensino. Percebe-se que professores comprometidos se reinventam, procuram meios tecnológicos de qualidade para aulas interativas e desenvolvem competências necessárias a esta nova realidade, para manutenção da qualidade do ensino. No enfrentamento dessa crise sanitária e humanitária, "a sociedade é forçada a lidar com a imprevisibilidade. O isolamento cria novos hábitos e comportamentos, tanto nas famílias quanto nas instituições de ensino, as quais são praticamente obrigadas a rever uma série de processos, de estruturas e de metodologias" (OLIVEIRA,2020, p. 65).

De acordo com a BNC-Professores (BRASIL, 2019), a formação do professor deve contemplar três eixos: o conhecimento, a prática e o engajamento (grifo nosso). No conhecimento, o professor deve dominar os conteúdos como também ensiná-los, demostrar conhecimento nos processos de aprendizagem, reconhecer diferentes contextos e atender à governança e às estruturas do sistema educacional. $\mathrm{Na}$ prática, deve saber planejar ações de ensino que resultem na real aprendizagem, gerir e criar um ambiente de aprendizagem, avaliá-lo e, assim, conduzir práticas pedagógicas, habilidades e competências previstas no currículo. Já, no engajamento, há comprometimento com o seu desenvolvimento profissional e com a aprendizagem de seus alunos, na crença de que todos são capazes de aprender, de participar dos processos na escola, de auxiliar na elaboração do projeto pedagógico e na construção dos valores democráticos, mostrando-se um profissional comprometido com os colegas, famílias e comunidade escolar.

Essas ações surgiram pelas deficiências nos cursos de formação de professores, por conta da enormidade teórica e da raridade prática nos currículos dos cursos de licenciatura, o que resulta grande dificuldade aos recém-professores na escola. António Nóvoa define, nos termos a seguir, a formação inicial de professores:

Por isso, insisto na necessidade de devolver a formação de professores aos professores, porque o reforço de processos de formação baseadas na investigação só faz sentido se eles forem construídos dentro da profissão. Enquanto forem apenas injunções do exterior, serão bem pobres as mudanças que terão lugar no interior do campo profissional docente (NÓVOA, 2009, p. 15). 
Por conta disso, a formação inicial e continuada de professores deve estar em sintonia com as escolas e com o sistema educacional, visto que as demandas da sociedade e as transformações que vêm ocorrendo com a Covid-19 afetam diretamente a educação em geral como também a formação do professor, resultando um profissional com perfil multifacetado, sempre aberto à construção e desconstrução de aprendizados. Desse ponto de vista, com as consequências da Covid-19, as escolas e os professores precisaram adaptar não apenas a forma de ensinar, para dar conta dos conteúdos, mas também os processos avaliativos.

Como já foi referido, neste momento especialmente, os professores precisam estimular ainda mais a autonomia, a proatividade e o protagonismo de seus alunos. Seguramente, com a suspensão das aulas presenciais, devido à pandemia, fez emergir um novo perfil de aluno, de professor e de escola.

A BNCC apresenta habilidades e competências que podem ser adaptadas ao ensino remoto. Entre essas habilidades e competências, destaca-se que os professores procurem desenvolver atividades que "possibilitem entender as relações próprias do mundo do trabalho e fazer escolhas alinhadas ao exercício da cidadania e ao seu projeto de vida, com liberdade, autonomia, consciência crítica e responsabilidade" (BRASIL, 2018, p. 9).

O que se vivencia durante a pandemia traz várias reflexões. Uma delas é que "ensinar sempre foi difícil, mas nos dias de hoje passou a ser ainda mais difícil” (IMBERNÓN, 2009, p. 90) e que as tecnologias estão sendo o principal meio para que a educação não pare nesse período, além de aproximarem as pessoas em meio ao isolamento social. No entanto, entre erros e acertos, os professores se encontram numa busca por um ensino de qualidade. Por isso, destaca-se que a formação do professor se constitui em "um processo complexo, contínuo, marcado por oscilações e descontinuidades e não por uma série de acontecimentos lineares" (LIMA; REALI, 2010, p. 221).

Com base nessas constatações, reafirma-se a importância da formação continuada e do trabalho coletivo entre colegas de escola, para minimizar o desgaste gerado por esse contexto atípico. Não se possui uma receita pronta de como se pode ensinar melhor, pois cada turma, cada ano e cada aluno são totalmente diferentes. O que ontem era uma verdade, hoje poderá não ser. Quem trabalha com a educação está sempre em constante aprendizado e nunca estará totalmente preparado para as incertezas da vida. Portanto, é muito importante que o professor esteja em constante formação.

\section{LIÇÕES EXTRAÍDAS DO ATUAL CENÁRIO}

As mudanças fazem parte da cultura, da humanidade e da ciência. Talvez, o que mais surpreende é a rapidez com que essas mudanças ocorrem. Um dos fatores que acelerou essas mudanças foi, sem sombra de dúvida, a pandemia gerada pela Covid-19. Diante disso, questionam-se os impactos dessas mudanças na escola e no ensino e, conforme explicitado no decurso deste texto, os desafios docentes, em tempo de mudanças, são muitos. 
Por outro lado, observa-se que a sociedade começa a revalorizar a pessoa do professor, especialmente, os pais que, de um dia para outro, tornaram-se "professores" de seus próprios filhos. Identificaram aí a importância do tato pedagógico inerente à docência e que, naturalmente, flui na ação do professor. Com isso, passou-se a ressignificar também a aula presencial e a escola como espaço de socialização.

Junto com o ensino remoto, intensificaram-se as novas tecnologias, caracterizadas como metodologias ativas que, para muitos professores, foram e continuam sendo um desafio. No campo tecnológico, não haverá retrocesso, mas as tecnologias são apenas meios que podem potencializar a aprendizagem dos estudantes. Deve-se reforçar que o sentido da educação é a formação humana e não o domínio tecnológico propriamente dito.

Nesses termos, não há dúvida de que a formação humana de crianças e jovens está relacionada ao cotidiano da escola, à sala de aula e ao fazer pedagógico do professor. Nesse processo, antes de tudo, o que importa é a vida das pessoas. Pode-se, portanto, questionar como a escola tem contribuído nesse tempo de pandemia para auxiliar as pessoas a preservarem a saúde.

O trabalho pedagógico é de prospecção nos saberes de ensinar. É uma tarefa incansável "para descobrir como, a partir de sua coerência interna, de sua epistemologia de referência e das limitações que lhe impõe a situação escolar, pode-se inventar meios para torná-los acessíveis aos outros sujeitos que já são capazes de dominá-los” (MEIRIEU, 2002, p. 83). A necessidade de inventar meios para tornar o conhecimento acessível aos estudantes retrata adequadamente a situação vivenciada no momento atual. Isso mostra também que a escola precisa ser flexível às mudanças sociais.

Nesse contexto, é oportuno retomar o pensamento de Morin (2000), a respeito dos saberes necessários à educação do futuro. $\mathrm{O}$ autor descreve sete desses saberes, resumidos da seguinte forma: as cegueiras do conhecimento; os princípios do conhecimento pertinente; ensinar a condição humana; ensinar a identidade terrena; enfrentar as incertezas; ensinar a compreensão e a ética do gênero humano. Cada saber tem seus desdobramentos, dos quais elegemos três (3) que podem contribuir para a compreensão desse momento de crise sanitária e humanitária: enfrentar as incertezas, ensinar a condição humana e a educação na era planetária.

Assim, a ideia de enfrentar as incertezas, com relação ao conhecimento, leva à reflexão sobre uma incoerência existente dentro da instituição escolar, ao decidir ensinar somente as "certezas". Porém, a vida se constituiu de ambas: “Navegamos num mar de incertezas, em meio a arquipélagos de certezas", afirma Morin (2000, p. 79). A própria pandemia, causada pela Covid-19, é um fato inesperado que, em processo de aprendizado, ainda não se sabe como será. Para tanto, questiona-se: quando a vida vai retornar à normalidade? E, se não houver normalidade, como continuar? A certeza que se tem é que, neste crucial momento, cabe o enfrentamento dessas incertezas, para que, quando o retorno for possível, metas sejam traçadas para seguir adiante.

Quando o autor se refere a ensinar a condição humana, refere-se à educação e ao ensino como algo universal, que leva em consideração a identidade humana que, para ele, é ignorada. Isso não 
deveria acontecer, pois o ser humano é parte constituinte essencial da sociedade e vice-versa, ou seja, o ser humano se constitui como parte de uma sociedade e como integrante de uma espécie (MORIN, 2000). Nessa sociedade e nessa espécie, as interações que se estabelecem são vivenciadas como indivíduos, como humanos. Neste particular e extraordinário momento de isolamento, mais do que nunca se deve levar em consideração a condição humana. Santos (2020, p. 31) alerta que, “[...] há muito mais vida no planeta do que a vida humana, já que esta representa apenas $0,01 \%$ da vida existente no planeta". Soma-se a isso o fato de o ser humano considerar-se o topo da escala evolutiva, contudo, agora, amedronta-se com as duras ameaças de um ser invisível. Com isso, pode-se inferir que, num futuro próximo ou remoto, outras formas de vidas, cada vez mais letais, deverão ameaçar a vida humana.

Diante desse paradoxo, quando Morin (2000) se refere à educação na era planetária, o sistema educacional, nomeadamente cartesiano, calcado na separação dos conhecimentos em disciplinas, que pouco ou nada comunicam entre si, está explicitando respostas aos problemas atuais. Aprendeu-se a analisar, a separar, mas não se aprendeu a relacionar os conhecimentos para uso efetivo na vida e como, com isso, melhorá-la. Nesse sentido, a pandemia da Covid-19 evidencia que, na educação, o que importa não é o que se sabe em quantidade de conteúdo, mas a forma como se age, a decisão de como se melhora a própria vida e a do outro; em especial, como se é solidário em relação ao outro em tempos extremos de isolamento social, como o que ora se vive.

Assim, os sete saberes da educação, referidos por Morin (2000) há duas décadas, ainda são muito atuais e provocam reflexões singulares para a educação. Espera-se que os desafios educacionais, atualmente vividos, contribuam para que se possa perceber que "a pandemia e a quarentena estão a revelar que são possíveis alternativas, que as sociedades se adaptam a novos modos de viver quando tal é necessário ao bem comum" (SANTOS, 2020, p. 29).

Dessa forma, as incertezas e inquietações, neste momento, experienciadas pela sociedade humana num tempo de quarentena coletiva, constituam-se positivamente pelo repensar das finalidades da educação e pela própria consciência de compromisso educacional dos professores, para a plena e necessária revalorização de seu fundamental e intransferível papel profissional.

\section{CONSIDERAÇÕES FINAIS}

A relevância do tema abordado é inegável, especialmente pelo atual cenário de incerteza, ocasionado pela crise sanitária e humanitária em virtude da pandemia Covid -19. Os desafios para a escola são muitos. Porém, maiores parecem ser os desafios à prática docente, pois as mudanças no sistema educacional iniciam pela motivação e disponibilidade do professor sem, contudo, restringirem-se a elas.

É importante destacar que essa mudança é complexa e não se pode resumi-la ao uso de ferramentas virtuais, substituindo o ensino presencial pelo remoto. Se não houver um câmbio no sistema escolar, bem como na prática do próprio professor, em relação à concepção da finalidade da educação, 
ter-se-á, unicamente, a forma tradicional de ensino transmissivo e de aprendizagem passiva, apenas em outra plataforma.

Para que essa mudança exigida possa ocorrer, é necessário que o professor tenha espaço e tempo para constituir-se professor. Isso envolve a formação profissional continuada, abrangendo todos os aspectos, o cognitivo, o metodológico, o profissional. Portanto, além de uma formação de qualidade, é necessária a qualidade das condições da instituição na qual o professor atua. É um trabalho coletivo, solidário, que necessita o apoio dos gestores, dos pais e da família dos alunos. Há um longo caminho a percorrer, mas há muitos indicativos de que essa caminhada já iniciou.

Dessa forma, não há dúvida de que aprender a cuidar de si, para poder ensinar os outros, é a competência mais necessária neste crucial momento. Portanto, reafirma-se o compromisso profissional, a dedicação e a constante formação para uma escola que prepare o aluno a diferentes contextos e situações. Espera-se, de fato, que a quarentena compulsória da pandemia brinde a sociedade com uma educação para a vida, com mais plenitude, mais respeito à diversidade e mais empenho a um ensino de qualidade para todos.

\section{REFERÊNCIAS}

BARBOSA, M. C. S.; HORN, M. das G. Projetos pedagógicos na educação infantil. Porto Alegre: Artmed, 2008.

BEHRENS, M. A. Paradigma da complexidade: metodologia de projetos, contatos didáticos e portfólios. 2. ed. Petrópolis, RJ: Vozes, 2008.

BLANCHARD, M.; MUZÁS, M.D. Los proyectos de aprendizaje: un marco metodológico clave para la innovación. Madrid: Narcea, 2016.

BRASIL. Conselho Nacional de Educação. Lei n. 9.394 de 20 de dezembro de 1996. Estabelece as Diretrizes e Bases da Educação Nacional. Diário Oficial [da] República Federativa do Brasil. Brasília, DF, 23 dez. 1996.

BRASIL. Base Nacional Comum Curricular (BNCC). Educação é a Base. Brasília, MEC/CONSED/UNDIME, 2018. Disponível em: https://bit.ly/3n4NGNW. Acesso em: 05 jul. 2020.

BRASIL. Conselho Nacional de Educação. Diretrizes Curriculares Nacionais para a Formação Inicial e Continuada de Professores da Educação Básica: BNC-Formação, 2019. Disponível em: https://bit.ly/32unaWj. Acesso em: 05 jul. 2020. 
DAHER, V. A Fiocruz diante da Covid-19. Entrevistada: Nísia Trindade Lima. Ciência Hoje, Rio de Janeiro, ed. 365, p. 6-9, maio, 2020.

DEMO, P. Educação e conhecimento. 3.ed. Petrópolis, RJ: Vozes, 2008.

FAZENDA, I. C. A. Integração e interdisciplinaridade no ensino brasileiro: efetividade ou ideologia. 5. ed. São Paulo: Loyola, 2002.

GIL, A. C. Como elaborar projetos de pesquisa. 6.ed. São Paulo: Atlas, 2017.

IMBERNÓN, F. Formação permanente do professorado: novas tendências. São Paulo: Cortez, 2009.

KURTZ, J. 'YouTubers' entra para dicionário. Disponível em: https://glo.bo/2IcM1qW. Acesso em: 18 out. 2020 .

LIMA, S. M.; REALI, A. M. M. R. O papel da formação básica na aprendizagem profissional da docência (aprende-se a ensinar no curso de formação básica?). In: REALI, A. M. M. R; MIZUKAMI, M. G. N. (Eds.). Formação de professores, práticas pedagógicas e escola. São Carlos: EdUFSCar, 2010.

LIMA, V. M. do R. Aula expositiva. In: GRILLO, M. C. et al. A gestão da aula universitária na PUCRS. Porto Alegre: EdiPUCRS, 2008. p. 99- 102.

LOPES, A. O. Aula expositiva: superando o tradicional. In: VEIGA, I. P. A. Técnicas de ensino: por que não? Campinas, SP: Papirus, 2011.

MEIRIEU, P. A Pedagogia entre o dizer e o fazer: a coragem de começar. Porto Alegre: Artmed, 2002.

MORIN, E. Os sete saberes necessários à educação do futuro. São Paulo: Cortez; Brasília, DF: UNESCO, 2000.

NÓVOA, A. Professores imagens do futuro presente. Lisboa: Educa, 2009.

OLIVEIRA, S. R. F de (org.). Escolas em quarentena: o vírus que nos levou para casa. Londrina, PR: Madrepérola, 2020. 
PIMENTA, S. G.; LIMA, M. S. L. Estágio e docência. 7. ed. São Paulo: Cortez, 2012.

SANTOS, B. de S. A cruel pedagogia do vírus. Portugal: Almedina, 2020.

SEVERINO, A. J. Metodologia do trabalho científico. 23. ed. ver. atual. São Paulo: Cortez, 2007.

TODOS PELA EDUCAÇÃO. Análise e visão do Todos Pela Educação sobre a adoção de estratégias de ensino remoto frente ao cenário de suspensão provisória das aulas presenciais. 2020. Disponível em: https://bit.ly/35dclcX. Acesso em: 3 jul. 2020. 
